\title{
LIV. On the changes of temperature produced by the rarefaction and condensation of air
}

\section{J.P. Joule Esq.}

To cite this article: J.P. Joule Esq. (1845) LIV. On the changes of temperature produced by the rarefaction and condensation of air , Philosophical Magazine Series 3, 26:174, 369-383, DOI: $10.1080 / 14786444508645153$

To link to this article: http://dx.doi.org/10.1080/14786444508645153

曲 Published online: 30 Apr 2009.

Submit your article to this journal $₫$

Џll Article views: 29

Q View related articles $\square$

Citing articles: 1 View citing articles ๘ 
IIV. On the Changes of Temperature produced by the Rarefaction and Condensation of Air. By J. P. JovLe, Esq.* $\mathrm{N}$ a paper + which was read before the Chemical Section of 1 the British Association at Cork, I applied Dr. Faraday's fine discovery of magneto-electricity in order to establish definite relations between heat and the ordinary forms of mechanical power. In that paper it was demonstrated experimentally that the mechanical power exerted in turning a magnetoelectrical machine is converted. into the heat evolved by the passage of the currents of induction through its coils; and, on the other hand, that the motive power of the electro-magnetic engine is obtained at the expense of the heat due to the chemical reactions of the battery by which it is worked. I hope, at a future period, to be able to communicate some new and very delicate experiments, in order to ascertain the mechanical equivalent of heat with the accuracy which its importance to physical science demands. My present object is to relate an investigation in which $I$ believe $I$ have succeeded in successfully applying the principles before maintained to the changes of temperature arising from the alteration of the density of gaseous bodies, - an inquiry of great interest in a practical as well as theoretical point of view, owing to its bearing upon the theory of the steam-engine.

Dr. Cullen and Dr. Darwin appear to have been the first who observed that the temperature of air is decreased by rarefaction and increased by condensation. Other philosophers have subsequently directed their attention to the subject. Dalton was, however, the first who succeeded in measuring the change of temperature with some degree of accuracy. By the employment of an exceedingly ingenious contrivance, that illustrious philosopher ascertained that about $50^{\circ}$ of heat are

* Communicated by the Author.

+ Phil. Mag. S. 3. vol. xxiii. pp. 263, 347, 435.

Phil. Mag. S. 3. Vol, 26. No. 174. May 1845. $2 \mathrm{C}$ 
370 Mr. Joule on the Changes of Tempcrature produced by

evolved when air is compressed to one-half of its original bulk; and that, on the other hand, $50^{\circ}$ are absorbed by a corresponding rarefaction*.

There is every reason for believing that Dalton's results are very near the truth, especially as they have been exactly confirmed by the experiments of Dr. Ure with the thermometer of Breguet. But our knowledge of the specific heat of elastic fluids is of such an uncertain character, that we should not be justified in attempting to deduce from them the absolute quantity of heat evolved or absorbed. I have succeeded in removing this difficulty by immersing my condensing pump and receiver into a large quantity of water, so as to transfer the calorific effect to a body which is universally received as the standard of capacity.

My apparatus will be understood on inspecting fig. J. C

Fig. 1.

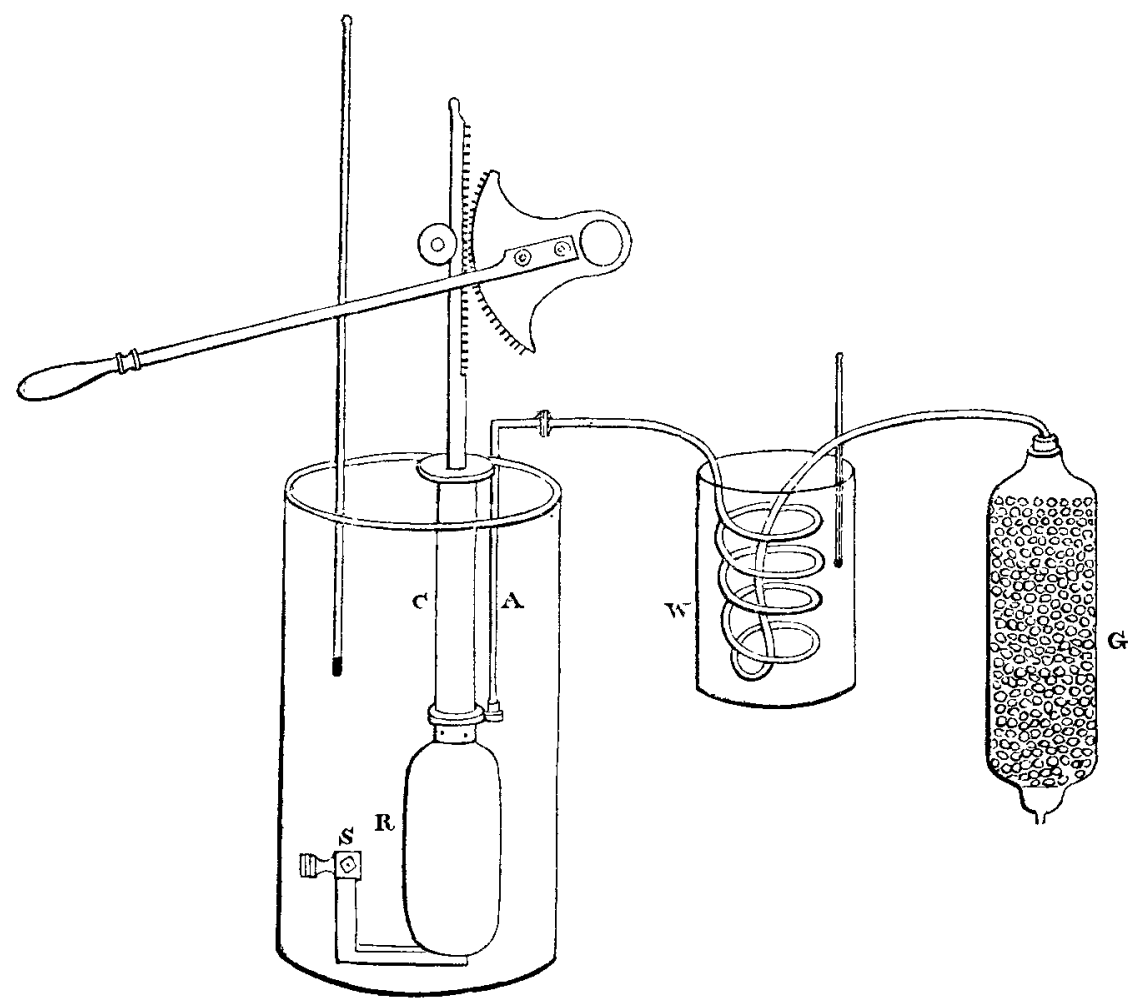

- Memoirs of the Literary and Philosophical Society of Manchester, vol. v. part 2. p. 521-525. 
represents the condensing pump, consisting of a cylinder of gun-metal, and of a piston fitted with a plug of oiled leather, which works easily, yet lightly, through a stroke of 8 inches. The cylinder is $10 \frac{1}{2}$ inches long, $1 \frac{3}{8}$ inch in interior diameter, and $\frac{1}{4}$ of an inch in thickness of metal. The pipe A, for the admission of air, is fitted to the lower part of the cylinder; at the bottom of this pipe there is a conical valve, constructed of horn, opening downwards. A copper receiver, $R$, which is 12 inches long, $4 \frac{1}{2}$ inches in exterior diameter, $\frac{1}{4}$ of an inch thick, and has a capacity of $136 \frac{1}{2}$ cubic inches, may be screwed upon the pump at pleasure. This receiver is furnished with a conical valve of horn opening downwards, and, at the bottom, with a piece of brass, B, along the centre of which there is a bore of $\frac{1}{8}$ th of an inch diameter. There is a stop-cock at $\mathrm{S}$ which I shall describe more particularly in the sequel.

Anticipating that the changes of temperature of the large quantity of water which was necessary in order to surround the receiver and pump would be very minute, I was at great pains in providing a thermometer of extreme sensibility and very great accuracy. A tube of narrow bore having been selected, a column of mercury, 1 inch long, was introduced, and gradually advanced in such a manner that the end of the column in one position coincided with the beginning of the column in the next. In each position the length of the column was ascertained to the $\frac{1}{4 \overline{0} \overline{0}}$ th part of an inch, by means of an instrument invented for the purpose by Mr. Dancer*. Afterwards the tube was covered with a film of bees'-wax, and each of the previously measured spaces was divided into twenty equal parts by means of a steel point carried by the dividing instrument; it was then etched by exposure to the vapour of fluoric acid. The scale thus formed was entirely arbitrary, and as it only extended between $30^{\circ}$ and $90^{\circ}$, it was necessary to compare the thermometer with another, constructed in the same manner, but furnished with a scale including the boiling as well as the freezing point. When this was done, it was found that ten divisions of the sensible thermometer (occupying about $\frac{1}{2}$ an inch) were nearly equal to the degree of Fahrenheit; therefore, since by practice I can easily estimate with the naked eye $\frac{1}{2}$ th of each of these divisions, I conld with this instrument determine temperatures to the $\frac{1}{2} 0$ th part of a degree. The scale being arbitrary, the indications of the

* Of the firm of Auraham and Dancer, Cross Street, Manchester. I have great pleasure in acknowledging here the skill displayed by this gentleman in the construction of the different parts of my apparatus; to it I must, in a great measure, attribute whatever success has attended the experiments detailed in this paper. 
thermometer had to be reduced in every instance, a circumstance which accounts for my having given the temperatures in the tables to three places of decimals.

It was important to employ, for the purpose of containing the water, a vessel as impermeable to heat as possible. With this view, two jars of tinned iron, one of them every way an inch smaller than the other, having been provided, the smaller jar was placed within the larger one, and the interstice between the two was closed hermetically. By this means a stratum of air of nearly the same temperature as the water was kept in contact with the sides and bottom of the inner jar. The jars used in the other experiments which I shall bring forward were constructed in a similar manner. Among other precautions to ensure accuracy, proper screens were placed between the vessels of water and the experimenter.

My first experiments were conducted in the following manner:-The pump and copper receiver were immersed into $4.5 \mathrm{lbs} .3 \mathrm{ozs}$. of water, into which the very sensible thermometer above described was then placed; whilst two other thermometers were ernployed in order to ascertain the temperature of the room and that of the water contained by the vessel $W$. Having stirred the water thoroughly, its temperature was carefully read off. The pump was then worked at a moderate degree of speed until abont twenty-two atmospheres of air, dried by being passed through the vessel $G$ full of small pieces of chloride of calcium, were compressed into the copper receiver. After this operation (which occupied from fifteen to twenty minutes) the water was stirred for five minutes so as to diffuse the heat equably through every part, and then its temperature was again read off.

The increase of temperature thus observed was owing partly to the condensation of the air, and partly also to the friction of the pump and the motion of the water during the process of stirring. To estimate the value of the latter sources of heat, the air-pipe $A$ was closed, and the pump was worked at the same velocity and for the same time as before, and the water was afterwards stirred precisely as in the first instance. The consequent increase of temperature indicated heat due to friction, \&c.

The jar was now removed, and the receiver having been immersed into a pneumatic trough, the quantity of air which had been compressed into it was measured in the usual manner, and then corrected for the force of vapour, \&c. The result, added to 136.5 cubic inches, the quantity contained by the receiver at first, gave the whole quantity of compressed air. 
TABLE I.

\begin{tabular}{|c|c|c|c|c|c|c|c|c|c|}
\hline \multirow{2}{*}{ Source of heat. } & \multirow{2}{*}{ 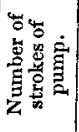 } & \multirow{2}{*}{ 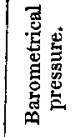 } & \multirow{2}{*}{ 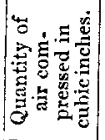 } & \multirow{2}{*}{ 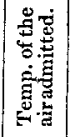 } & \multirow{2}{*}{ 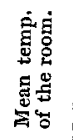 } & \multirow{2}{*}{ Difference. } & \multicolumn{2}{|c|}{ Temp. of water. } & \multirow{2}{*}{ 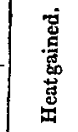 } \\
\hline & & & & & & & $\begin{array}{l}\text { Before } \\
\text { expt. }\end{array}$ & $\begin{array}{l}\text { After } \\
\text { expt. }\end{array}$ & \\
\hline Condensation, \&c. & 300 & 30.06 & 3047 & $56^{\circ} 2$ & $57 \cdot 5$ & $\grave{2} \cdot 224-$ & $54 \cdot 930$ & $55 \cdot 622$ & $0 \cdot 692$ \\
\hline Friction, \&c. ...... & 300 & & & & $57 \cdot 5$ & $1 \cdot 685$ & $55 \cdot 652$ & $55 \cdot 979$ & 0.327 \\
\hline Condensation, \&c. & 300 & $30 \cdot 07$ & 2924 & $54 \cdot 8$ & $53 \cdot 5$ & $0817+$ & 53.970 & $54 \cdot 664$ & 0694 \\
\hline Friction, \&c. ...... & 300 & & & & $54 \cdot 5$ & $0.358+$ & $54 \cdot 675$ & $55 \cdot 042$ & $0 \cdot 367$ \\
\hline Condensation, \&c. & 300 & $30 \cdot 24$ & 2870 & 537 & $52 \cdot 5$ & $0.380+$ & $52 \cdot 562$ & $53 \cdot 197$ & 0.635 \\
\hline Friction, \&c. ....... & 300 & & & & $52 \cdot 6$ & $0 \cdot 760+$ & $53 \cdot 197$ & $53 \cdot 524$ & $0: 327$ \\
\hline Condensation, \&c. & 300 & $30 \cdot 07$ & 2939 & $58 \cdot 8$ & $57 \cdot 5$ & $1.794-$ & $55 \cdot 359$ & $56 \cdot 053$ & $0 \cdot 694$ \\
\hline Friction, \&c. ....... & 300 & & & & $57 \cdot 75$ & $1 \cdot 536-$ & $56 \cdot 053$ & $56 \cdot 375$ & 0.322 \\
\hline Condensation, \&c. & 300 & $30 \cdot 34$ & 2924 & $55 \cdot 7$ & $53 \cdot 5$ & $2 \cdot 184+$ & $55 \cdot 409$ & $55 \cdot 959$ & 0.550 \\
\hline Friction, \&c. ....... & 300 & & & & $53 \cdot 75$ & $2 \cdot 316+$ & $55 \cdot 962$ & {$[56 \cdot 170 \mid$} & 0.208 \\
\hline Condensation, \&c. & 300 & $30 \cdot 40$ & 3033 & $58 \cdot 1$ & $60 \cdot 0$ & $0 \cdot 174+$ & $59 \cdot 876$ & $60 \cdot 472$ & 0.596 \\
\hline Friction, \&c. ....... & 300 & $\ldots \ldots$ & & & $60 \cdot 4$ & $0 \cdot 196+$ & 60478 & $60 \cdot 713$ & 0.235 \\
\hline $\left.\begin{array}{c}\text { Condensation } \\
\text { mean } \ldots \ldots \ldots . . .\end{array}\right\}$ & 300 & $|30 \cdot 20|$ & 2956 & $56^{2} 2$ & & $0.078-$ & & & 0.643 \\
\hline Friction, \&c, mean & 300 & & & & ...... & $0.068+$ & & & $0 \cdot 297$ \\
\hline Corrected result. & & $30 \cdot 20$ & 2956 & & & & & & $0 \cdot 344$ \\
\hline
\end{tabular}

The result given in the above Table is the difference between the effects of condensation and friction alone, corrected for the slight superiority of the cooling influence of the atmosphere in the experiments on friction. We must now, however, proceed to apply a further correction, on account of the circumstance that the friction of the piston was considerably greater during the condensing experiments than during the experiments to ascertain the effect of friction. In the latter case the piston worked with a vacuum beneath it, whilst in the former the leather was pressed to the sides of the pump by a force of condensed air, averaging 32 lbs. per square inch. I endeavoured to estimate the difference between the friction in the two cases, by removing the valve of the receiver and working the pump with about 32 lbs. per square inch pressure below it. These experiments, alternated with others in which a vacuum was beneath the piston, showed that the heat given out in the two cases was, as nearly as possible, in the ratio of six to five. When the correction indicated in this manner has been applied to $0^{\circ} .297$ (see Table) and the result subtracted from $0^{\circ} \cdot 643$, we obtain $0^{\circ} \cdot 285$ as the effect of compressing 2956 cubic inches of dry air at a pressure of 30.2 inches of mercury, into the space of 136.5 cubic inches.

This heat was distributed through $45 \mathrm{lbs} .3 \mathrm{ozs}$. of water, 


\section{Mr. Joule on the Changes of Temperature produced by}

$20 \frac{1}{2} \mathrm{lbs}$. of brass and copper, and $6 \mathrm{lbs}$. of tinned iron. It was therefore equivalent to $13^{\circ} \cdot 628$ per $\mathrm{lb}$. avoirdupois of water.

The force necessary to effect the above condensation may be easily deduced from the law of Boyle and Mariotte, which has been proved by the French academicians to hold good as far as the twenty-fifth atmosphere of pressure. Let fig. 2 represent a cylinder closed at one end, the length of which is $21 \cdot 654$ feet, and the sectional area 11.376 square inches. Then one foot of it will have exactly the same capacity as the copper receiver used in the experiments, and its whole capacity will be 2956 cubic inches. It is evident, therefore, that the force used in

Fig. 2.

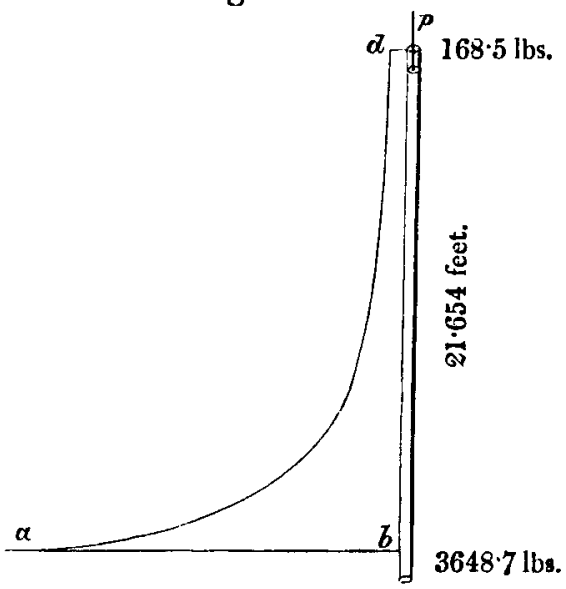
pumping (considered to be without friction) was exactly equal to that which would push the piston $p$ to the distance of a foot from the bottom of the cylinder. Excluding exterior atmospheric pressure, the force upon the piston, when at the top of the cylinder, will be 168.5 lbs., the weight of a column of mercury 30.2 inches long and of 11.376 square inches section; and at a foot from the bottom it will be $21 \cdot 654$ times as much, or $3648.7 \mathrm{lbs}$. The hyperbolic area, $a b c d$, will therefore represent the force employed in the condensation, including the assistance of the atmospheric pressure. Applying the formula for hyperbolic spaces, we have,

$$
s=3648 \cdot 7 \times 2 \cdot 302585 \times \log 21 \cdot 654=11220 \cdot 2 .
$$

The force expended in condensation was therefore equivalent to that which can raise $11220 \cdot 2$ lbs. to the perpendicular height of one foot.

Comparing this with the quantity of heat evolved, we have $\frac{11220 \cdot 2}{13^{\circ} \cdot 628}=\frac{823}{1^{\circ}}$. So that a mechanical force capable of raising $823 \mathrm{lbs}$. to the height of one foot must be applied in the condensation of air, in order to increase the temperature of a pound of water by one degree of Fahrenheit's scale.

The following Table contains the results of experiments si- 
milar to the last, except in the extent to which the compression of the air was carried.

TABLE II.

\begin{tabular}{|c|c|c|c|c|c|c|c|c|c|}
\hline \multirow{2}{*}{ Source of heat. } & \multirow{2}{*}{ 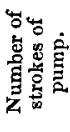 } & \multirow{2}{*}{ 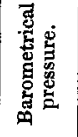 } & \multirow{2}{*}{ 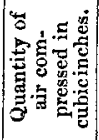 } & \multirow{2}{*}{ 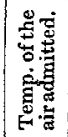 } & \multirow{2}{*}{ 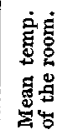 } & \multirow{2}{*}{ Difference. } & \multicolumn{2}{|c|}{ Temp. of water. } & \multirow{2}{*}{ 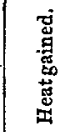 } \\
\hline & & & & & & & $\begin{array}{l}\text { Before } \\
\text { expt. }\end{array}$ & $\begin{array}{l}\text { After } \\
\text { expt. }\end{array}$ & \\
\hline Condensation, \&c. & 120 & $30 \cdot 40$ & 1410 & $54 \cdot 0$ & $54 \cdot 2$ & $0 \cdot 010+$ & 54.099 & $54 \cdot 322$ & 0.223 \\
\hline Friction, \&c. ...... & 120 & & & & $54 \cdot 6$ & $0.224-$ & $54 \cdot 332$ & $54 \cdot 421$ & 0.089 \\
\hline Condensation, \&c. & 120 & 3050 & 1467 & 566 & $56 \cdot 5$ & $0.308+$ & $56 \cdot 693$ & 56.923 & 0.230 \\
\hline Friction, \&c. ...... & 120 & J & & & 567 & $0.281+$ & 56.926 & $57 \cdot 036$ & 0.110 \\
\hline Condensation, \&c. & 120 & $30 \cdot 50$ & 1440 & $62 \cdot 6$ & $63 \cdot 6$ & $1 \cdot 763-$ & $61 \cdot 703$ & $6 \mathrm{I} \cdot 971$ & 0.268 \\
\hline Friction, \&c. ...... & 120 & & & & $64 \cdot 0$ & $1 \cdot 960$ & $61-976$ & $62 \cdot 105$ & 0.129 \\
\hline Condensation, \&c. & 120 & $30 \cdot 57$ & 1442 & $59 \cdot 0$ & $58 \cdot 4$ & $0.400+$ & $58 \cdot 680$ & $58 \cdot 921$ & 0241 \\
\hline Friction, \&c. ...... & 120 & & & & $58 \cdot 5$ & $0.477+$ & 58921 & 69.033 & 0.112 \\
\hline Condensation, \&c. & 120 & $29 \cdot 94$ & 1405 & $55 \cdot 2$ & $57 \cdot 0$ & $1.566-$ & $55 \cdot 310$ & $55 \cdot 558$ & 0.248 \\
\hline Friction, \&c. ...... & 120 & $\ldots \ldots$ & $\cdots \cdots$ & & $57 \cdot 2$ & $1.573-$ & 55.563 & $55 \cdot 692$ & $0 \cdot 129$ \\
\hline $\left.\begin{array}{c}\text { Condensation } \\
\text { mean } \ldots \ldots \ldots \ldots\end{array}\right\}$ & 120 & $30 \cdot 38$ & 1433 & $57 \cdot 5$ & ...... & $0.522-$ & & & 0.242 \\
\hline Friction mean ... & 120 & & & & ...... & $0 \cdot 600-$ & & & $0 \cdot 114$ \\
\hline Corrected result... & ...... & $30 \cdot 38$ & 1433 & & & & & & $0 \cdot 128$ \\
\hline
\end{tabular}

After applying the proper correction for the increase of friction during condensation, and reducing the result, as before, to the capacity of a lb. of water, I find $5^{\circ} \cdot 26$ to be the mean quantity of heat evolved by compression of air in the above series of experiments.

The mechanical force spent in the condensation is represented in this instance by

$$
s=1779.3 \times 2.302585 \times \log 10.498=4.183 .46 .
$$

Hence the equivalent of a degree of heat per lb. of water, as determined by the above series, is $795 \mathrm{lbs}$. raised to the height of one foot.

The mechanical equivalents of heat derived from the foregoing experiments were so near $838 \mathrm{lbs} . *$, the result of magnetical experiments in which "latent leat" could not be suspected to interfere in any way, as to convince me that the heat evolved was simply the manifestation, in another form, of the mechanical power expended in the act of condensation: I was still further confirmed in this view of the subject by the following experiments.

I provided another copper receiver (E, fig. 3) which had a capacity of 134 cubic inches. Like the former receiver, to

$$
\text { - Phil. Mag. S. 3. vol. xxiii. p. } 441 .
$$


which it could be connected by a coupling nut, it had a piece $D$ attached, in the centre of which there was a bore of $\frac{1}{6}$ th of an inch diameter, which could be closed perfectly by means of a proper stop-cock.

I must here be permitted to make a short digression, in order to explain the construction of the stop-cocks, as it may save those who may in future Fig. 3.

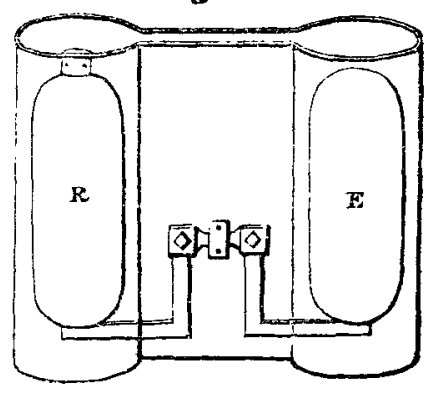
attempt similar experiments, the useless trouble of trying to make the ordinary stop-cock perfectly air-tight under high pressures. The one I have used is the invention of $\mathrm{Mr}$. Ash, of this town, a gentleman well known for his great mechanical genius; and he has in the most obliging manner allowed me to give a full description of it. Fig. 4 is a full-sized sectional view of the stop-cock. $a$ is a brass screw, by means of which a thick collar of leather, $l$, is very tightly compressed. The centre of $a$ is perforated with a female screw, in which a steel screw, $s$, works, the threads of which press so tightly against the leather collar as effectually to prevent any escape of air in that direction. The end of the steel screw is smooth and conical, and the conical hole $h$ is plugged with tin. When the stop-cock is shut, the smooth end of the steel screw presses against the soft Fig. 4.

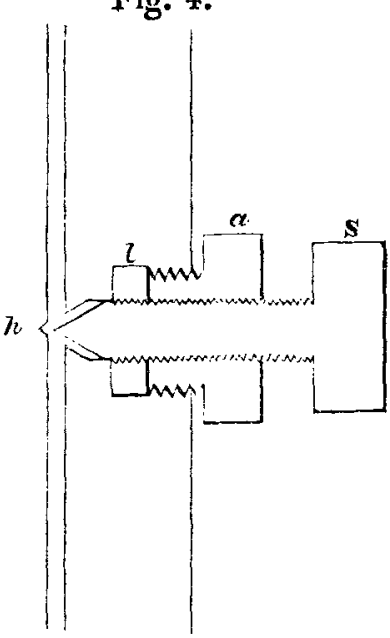
metal, so as to prevent the escape of the least particle of air ; but when opened, as represented in the figure, it leaves a passage for the air round the conical point. I have tested this stop-cock in the most severe manner, and have found it to answer perfectly.

Having filled the receiver $\mathrm{R}$ (fig. 3) with about 22 atmospheres of dry air, and having exhausted the receiver $\mathrm{E}$ by means of an air-pump, I screwed them together, and then put them into a tin can containing $16 \frac{1}{2} \mathrm{lbs}$. of water. The water 
was first thoroughly stirred, and its temperature taken by the same delicate thermometer which was made use of in the former experiments. The stop-cocks were then opened by means of a proper key, and the air allowed to pass from the full into the empty receiver until equilibrium was established between the two. Lastly, the water was again stirred and its temperature carefully noted. The following Table contains the results of a series of experiments conducted in this way, interpolated with others to eliminate the effects of stirring, evaporation, \&c.

TABLE III.

\begin{tabular}{|c|c|c|c|c|c|c|c|}
\hline \multirow{2}{*}{ Nature of expcriment. } & \multirow{2}{*}{ 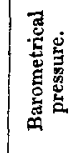 } & \multirow{2}{*}{ 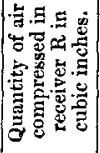 } & \multirow{2}{*}{ 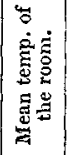 } & \multirow{2}{*}{ wifference. } & \multicolumn{2}{|c|}{ 'Temp. of water. } & \multirow{2}{*}{$\begin{array}{c}\text { Gain or loss of } \\
\text { heat. }\end{array}$} \\
\hline & & & & & $\begin{array}{l}\text { Before } \\
\text { expt. }\end{array}$ & $\begin{array}{l}\text { After } \\
\text { expt. }\end{array}$ & \\
\hline $\begin{array}{l}\text { Expansion ......... } \\
\text { Interpolation ..... } \\
\text { Expansion ......... } \\
\text { Interpolation ...... } \\
\text { Expansion ......... } \\
\text { Interpolation ...... } \\
\text { Expansion ......... } \\
\text { Interpolation ...... } \\
\text { Expansion ........ } \\
\text { Interpolation ...... } \\
\text { Expansion ......... }\end{array}$ &. $\mid \begin{array}{l}30 \cdot 20 \\
\ldots \ldots \\
30 \cdot 44 \\
\ldots \ldots \\
30 \cdot 44 \\
\ldots \ldots \ldots \\
30 \cdot 44 \\
\ldots \ldots \\
30 \cdot 46 \\
30 \cdot 50\end{array}$ & $\begin{array}{c}2910 \\
\ldots \ldots \ldots \\
2920 \\
\ldots \ldots \ldots \\
2910 \\
\ldots \ldots \ldots \\
2915 \\
\ldots \ldots \ldots \\
3200 \\
\ldots \ldots \ldots \\
2880\end{array}$ & $\begin{array}{l}57 \\
57 \cdot 0 \\
57 \cdot 0 \\
62 \cdot 0 \\
62 \cdot 1 \\
58 \cdot 5 \\
53 \cdot 6 \\
61 \cdot 3 \\
61 \cdot 3 \\
580 \\
58 \cdot 3\end{array}$ & $\begin{array}{l}0.118+ \\
0.906- \\
0.885- \\
0.783- \\
0.873- \\
0.233+ \\
0.132+ \\
0.787- \\
0.780- \\
0.186+ \\
0.110-\end{array}$ & $\begin{array}{l}57 \cdot 520 \\
56 \cdot 085 \\
56 \cdot 103 \\
61 \cdot 217 \\
61 \cdot 222 \\
58 \cdot 732 \\
58 \cdot 732 \\
60 \cdot 508 \\
60 \cdot 518 \\
58 \cdot 184 \\
58 \cdot 190\end{array}$ & $\left|\begin{array}{l}57 \cdot 517 \\
56 \cdot 103 \\
56 \cdot 128 \\
61 \cdot 217 \\
61 \cdot 232 \\
58 \cdot 735 \\
58 \cdot 732 \\
60 \cdot 518 \\
60 \cdot 523 \\
58 \cdot 187 \\
58 \cdot 190\end{array}\right|$ & $\begin{array}{l}0.003 \text { loss. } \\
0038 \text { gain. } \\
0.025 \text { gain. } \\
0 \\
0.010 \text { gain. } \\
0.003 \text { gain. } \\
0 \\
0.010 \text { gain. } \\
0.005 \text { gain. } \\
0.003 \text { gain. } \\
0\end{array}$ \\
\hline $\left.\begin{array}{c}\text { Mean of expts. } \\
\text { of expansion } \\
\text { Mean of inter- } \\
\text { polations ...... }\end{array}\right\}$ & $\begin{array}{l}30 \cdot 41 \\
\ldots \ldots\end{array}$ & 2956 & & $\begin{array}{l}0.400- \\
0.411-\end{array}$ & & & $\left\{\begin{array}{l}0.0062 \text { gain. } \\
0.0068 \text { gain. }\end{array}\right.$ \\
\hline Corrected result... & $30 \cdot 41$ & 2956 & & & & & 0 \\
\hline
\end{tabular}

The difference between the means of the experiments and interpolations being exactly such as was found to be due to the increased effect of the temperature of the room in the latter case, we arrive at the conclusion, that no change of temperature occurs when air is allowed to expand in such a manner as not to develope mechanical power.

In order to analyse the above experiments, $I$ inverted the receivers, as shown in fig. 5 , and immersed them, as well as the connecting piece, into separate cans of water. One of the receivers had 2828 cubic inches of dry air condensed into it, while the other was vacuous. After equilibrium was restored by opening the cocks, I found that $2 \cdot 36$ of cold per lb. of 
water had been produced in the receiver from which the air had expanded, while $2^{\circ} \cdot 38$ of heat had been produced in the other receiver, and $0^{\circ} .31$ of heat also in the can in which the connecting piece was immersed; the sum of the whole amounting nearly to zero. The slight redundance of heat was owing to the loss of Fig. 5.

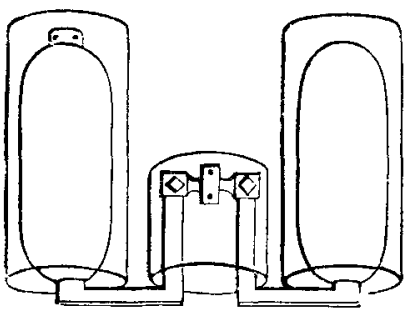
cold during the passage of the air from the charged receiver to the stop-cocks, through a part of the pipe which could not be immersed in water.

A series of experiments was now made in the following manner:-The receiver was filled with dry compressed air, and a coiled leaden pipe, $\frac{1}{4}$ of an inch in internal diameter and 12 yards long, was screwed tightly upon the nozle, as represented in fig. 6. The whole was then immersed into an oval

Fig. 6.

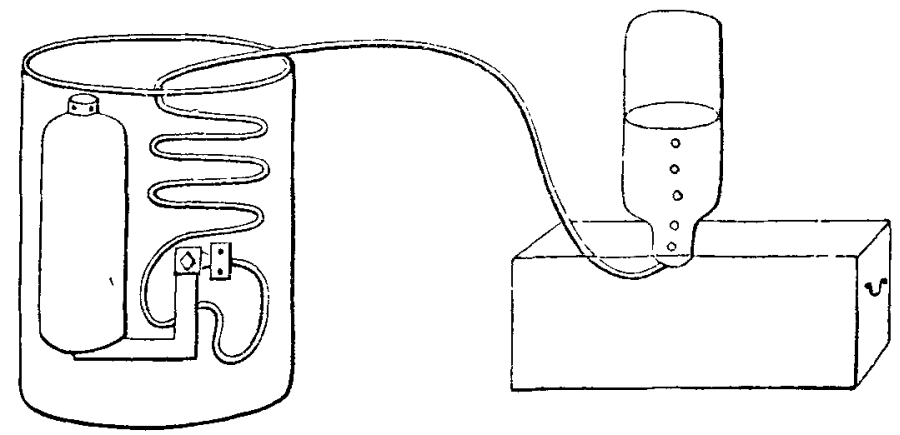

can, which was constructed as before described, and was also covered at top as perfectly as possible. Having ascertained the temperature of the water by means of the sensible thermometer before used, the stop-cock was opened and the air made to pass from the receiver through a pneumatic trough into a jar, by which it was carefully measured. After the air in the receiver had been reduced to the atmospherical pressure, the water was again well-stirred and its temperature noted. An interpolation was made after each of these experiments, in order to eliminate the effects of stirring, \&c. 
TABLE IV.

\begin{tabular}{|c|c|c|c|c|c|c|c|c|}
\hline \multirow{2}{*}{ Nature of experiment. } & \multirow{2}{*}{ 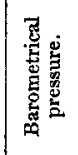 } & \multirow{2}{*}{ 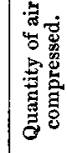 } & \multirow{2}{*}{ 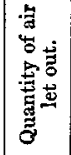 } & \multirow{2}{*}{ 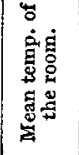 } & \multirow{2}{*}{ Difference. } & \multicolumn{2}{|c|}{ Temp. of water. } & \multirow{2}{*}{$\begin{array}{c}\text { Gain or loss of } \\
\text { heat. }\end{array}$} \\
\hline & & & & & & $\begin{array}{l}\text { Before } \\
\text { expt. }\end{array}$ & $\begin{array}{l}\text { After } \\
\text { expt. }\end{array}$ & \\
\hline Expansion & $30 \cdot 04$ & 2862 & 2726 & 557 & $0.405+$ & $56 \cdot 207$ & 56.004 & 0.203 loss. \\
\hline Interpolation & $\ldots \ldots$ & $\cdots$ & $\ldots \ldots$ & 55.4 & $0.579+$ & 56.004 & $55 \cdot 954$ & 0.050 loss. \\
\hline Expansion .... & $30 \cdot 10$ & 2807 & 2670 & $54 \cdot 6$ & $0 \cdot 022+$ & $54 \cdot 714$ & 54530 & $0 \cdot 184$ loss. \\
\hline Interpolation . & & ...... & & $54 \cdot 25$ & $0.276+$ & $54-536$ & 54.516 & 0020 loss. \\
\hline Expansion..... & $30 \cdot 10$ & 2723 & 2587 & $53 \cdot 6$ & $0 \cdot 760+$ & $54 \cdot 460$ & $54 \cdot 259$ & $0 \cdot 201$ loss. \\
\hline Interpolation $\ldots$ & & & $\ldots . .$. & 53.4 & $0.839+$ & $54 \cdot 259$ & 54.219 & 0.040 loss. \\
\hline Expansion .. & $30 \cdot 10$ & 2807 & 2670 & $49 \cdot 05$ & $0 \cdot 307+$ & $49 \cdot 456$ & 49.258 & $0^{\cdot} \cdot 198$ loss. \\
\hline Interpolation $\ldots$ & $\mid \ldots \ldots$ & 3030 & o...s & $49 \cdot 1$ & $0158+$ & $\begin{array}{l}49 \cdot 258 \\
50 \cdot 176\end{array}$ & $\begin{array}{l}49 \cdot 258 \\
50 \cdot 008\end{array}$ & \\
\hline $\begin{array}{l}\text { Expansion } \\
\text { Interpolation }\end{array}$ & $\left|\begin{array}{r}30 \cdot 23 \\
\ldots \ldots \ldots\end{array}\right|$ & $\begin{array}{l}3039 \\
\ldots \ldots\end{array}$ & $\left|\begin{array}{l}2903 \\
\ldots \ldots\end{array}\right|$ & $\begin{array}{l}50 \cdot 6 \\
51 \cdot 1\end{array}$ & $\begin{array}{l}0.508- \\
1.063-\end{array}$ & 50.176 & $\begin{array}{l}\mathbf{5 0} \cdot 008 \\
\mathbf{5 0} \cdot 057\end{array}$ & $\begin{array}{l}0.168 \text { loss. } \\
0.040 \text { gain. }\end{array}$ \\
\hline Expansion ...... & $30 \cdot 20$ & 2919 & 2782 & 49.0 & $0.355-$ & $48 \cdot 728$ & $48 \cdot 563$ & $0 \cdot 165$ loss. \\
\hline Interpolation ... & $\cdot \cdots \cdots$ & $\cdots \cdot \cdot$ & & $48 \cdot 85$ & $0.277-$ & $48 \cdot 573$ & $48 \cdot 573$ & 0 \\
\hline $\left.\begin{array}{c}\text { Mean of expts. } \\
\text { of expansion }\end{array}\right\}$ & $30 \cdot 13$ & 2859 & 2723 & & $0 \cdot 105+$ & & & $0 \cdot 1865$ loss. \\
\hline Mean of inter- $\}$ & & & & & $0.085+$ & & & 0.0117 loss. \\
\hline polations $\ldots J$ & & & & & & & & \\
\hline Cor & $.30 \cdot 13$ & 2859 & & & & & & $0 \cdot] 738$ loss \\
\hline
\end{tabular}

The cold produced was diffused through 21.17 lbs. of water, 14. lbs. of copper, $8 \mathrm{lbs}$. of lead, and $7 \mathrm{lbs}$. of tinned iron. Hence we find that a quantity of cold was produced in the experiments sufficient to cause the temperature of a $\mathrm{lb}$. of water to decrease by $4^{\circ} \cdot 085$. At the same time a mechanical force was developed, which could raise a column of the atmosphere, of an inch square at the base, to the altitude of 2723 inches; or in other words, could raise $3352 \mathrm{lbs}$. to the height of one foot. For each degree of heat lost, there was therefore generated a force sufficient to raise $820 \mathrm{lbs}$. to the height of one foot.

In the two following series the experiments were varied by compressing and measuring out different volumes of air.

On reducing the results of these experiments in the manner before indicated, we find that in the experiments of 'Table V. 814 lbs., and in those of Table VI. $760 \mathrm{lbs}$. were raised to the height of a foot, for every degree of heat per lb. of water lost.

These results are inexplicable if heat be a substance. If that were the case, the same quantity of heat would have been absorbed by the rarefaction which took place in the experiments of Table IV., as was evolved by the corresponding 
TABLE V.

\begin{tabular}{|c|c|c|c|c|c|c|c|c|}
\hline \multirow{2}{*}{ Nature of experiment. } & \multirow{2}{*}{ 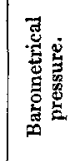 } & \multirow{2}{*}{ 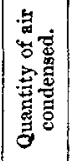 } & \multirow{2}{*}{ 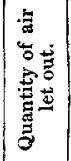 } & \multirow{2}{*}{ 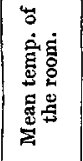 } & \multirow{2}{*}{ Difference. } & \multicolumn{2}{|c|}{ Temp. of watcr. } & \multirow{2}{*}{$\begin{array}{c}\text { Gain or loss of } \\
\text { heat. }\end{array}$} \\
\hline & & & & & & $\begin{array}{l}\text { Before } \\
\text { expt. }\end{array}$ & $\begin{array}{l}\text { After } \\
\text { expt. }\end{array}$ & \\
\hline 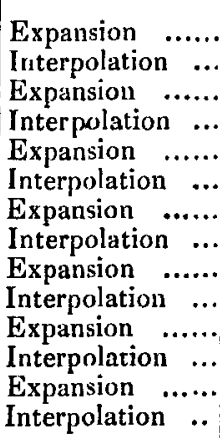 & $\left|\begin{array}{c}30 \cdot 06 \\
\ldots \ldots \\
30 \cdot 20 \\
\ldots \ldots \\
30 \cdot 28 \\
\ldots \ldots .28 \\
30 \cdot 28 \\
30 \cdot 30 \\
\ldots \ldots .2 \\
30 \cdot 27 \\
30 \cdot 14 \\
\ldots \ldots\end{array}\right|$ & $\begin{array}{l}1336 \\
\ldots \ldots \\
1343 \\
\ldots \ldots \\
1386 \\
\ldots \ldots \\
1387 \\
\ldots \ldots . \\
1434\end{array}$ & $\mid$\begin{tabular}{c|}
1200 \\
1206 \\
$\ldots \ldots$ \\
1250 \\
$\ldots \ldots$. \\
1250 \\
$\ldots \ldots$. \\
1298 \\
$\ldots \ldots$. \\
1268 \\
1260 \\
$\ldots \ldots$.
\end{tabular} & \begin{tabular}{|l|}
$52 \cdot 5$ \\
$52 \cdot 55$ \\
$53 \cdot 5$ \\
$53 \cdot 6$ \\
$52 \cdot 4$ \\
$52 \cdot 55$ \\
$52 \cdot 95$ \\
$53 \cdot 2$ \\
$59 \cdot 0$ \\
$58 \cdot 65$ \\
$55 \cdot 35$ \\
$55 \cdot 1$ \\
$55 \cdot 2$ \\
$55 \cdot 3$
\end{tabular} & $\begin{array}{l}0.441- \\
1 \cdot 460- \\
1 \cdot 385- \\
1.457- \\
0.419- \\
0.588- \\
0.778- \\
1.017- \\
0.610+ \\
0.888+ \\
0.227+ \\
0.534+ \\
0.313+ \\
0.158+\end{array}$ & $\begin{array}{l}51 \cdot 074 \\
51 \cdot 069 \\
52 \cdot 125 \\
52 \cdot 115 \\
52 \cdot 021 \\
51 \cdot 951 \\
52 \cdot 195 \\
52 \cdot 171 \\
59 \cdot 665 \\
59 \cdot 551 \\
55 \cdot 622 \\
55 \cdot 647 \\
55 \cdot 565 \\
55 \cdot 461\end{array}$ & $\begin{array}{l}50 \cdot 044 \\
51 \cdot 110 \\
52 \cdot 105 \\
52 \cdot 171 \\
51 \cdot 941 \\
51 \cdot 974 \\
52 \cdot 148 \\
52 \cdot 195 \\
59 \cdot 556 \\
59 \cdot 526 \\
55 \cdot 532 \\
55 \cdot 622 \\
55 \cdot 461 \\
55 \cdot 456\end{array}$ & $\begin{array}{l}0.030 \text { loss. } \\
0.041 \text { gain. } \\
0.020 \text { loss. } \\
0.056 \text { gain. } \\
0.080 \text { loss. } \\
0 \text { 023 gain. } \\
0.047 \text { loss. } \\
0.024 \text { gain. } \\
0.109 \text { loss. } \\
0.025 \text { loss. } \\
0.090 \text { loss. } \\
0.025 \text { loss. } \\
0.104 \text { loss. } \\
0.005 \text { loss. }\end{array}$ \\
\hline $\left.\begin{array}{c}\text { Mean of expts. } \\
\text { of expansion } \\
\text { Mean of inter- } \\
\text { polations ... }\end{array}\right\}$ & $30 \cdot 22$ & 1384 & 1248 & & $\begin{array}{l}0.410- \\
0.420-\end{array}$ & & & $\begin{array}{l}0.0686 \text { loss. } \\
0.0127 \text { gain. }\end{array}$ \\
\hline Corrected result . & $30 \cdot 22$ & 1384 & 1248 & $\ldots . .$. & & & & 0.081 loss. \\
\hline
\end{tabular}

Table VI.

\begin{tabular}{|c|c|c|c|c|c|c|c|c|}
\hline \multirow{2}{*}{ Nature of experiment. } & \multirow{2}{*}{ 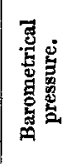 } & \multirow{2}{*}{ 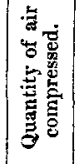 } & \multirow{2}{*}{ 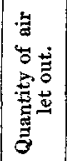 } & \multirow{2}{*}{ 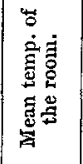 } & \multirow{2}{*}{ Difference. } & \multicolumn{2}{|c|}{ Temp. of water. } & \multirow{2}{*}{$\begin{array}{l}\text { Gain or loss of } \\
\text { heat. }\end{array}$} \\
\hline & & & & & & $\begin{array}{l}\text { Before } \\
\text { expt. }\end{array}$ & $\begin{array}{l}\text { After } \\
\text { expt. }\end{array}$ & \\
\hline 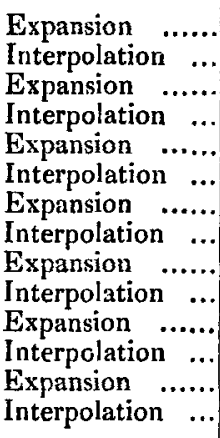 & $\begin{array}{c}30 \cdot 24 \\
\ldots \ldots \ldots \\
30 \cdot 20 \\
30 \cdot 15 \\
\ldots \ldots \\
30 \cdot 15 \\
\ldots \ldots \\
30 \cdot 20 \\
\ldots \ldots \ldots \\
30 \cdot 30 \\
30 \cdot 14 \\
\ldots \ldots .\end{array}$ & \begin{tabular}{|l|}
3116 \\
$\ldots \ldots \ldots$ \\
3198 \\
$\ldots \ldots \ldots$ \\
3192 \\
$\ldots \ldots \ldots$ \\
3143 \\
$2 \ldots 66$ \\
$\ldots \ldots$. \\
3160 \\
$\ldots \ldots \ldots$ \\
3188 \\
$\ldots \ldots$.
\end{tabular} & \begin{tabular}{|c}
1238 \\
$\ldots \ldots$ \\
1238 \\
$12 \ldots$ \\
1238 \\
$\ldots \ldots$ \\
1238 \\
$\ldots \ldots$ \\
1238 \\
$\ldots \ldots$ \\
1238 \\
$\ldots \ldots$
\end{tabular} & $\begin{array}{l}60 \cdot 1 \\
60 \cdot 2 \\
56 \cdot 1 \\
56 \cdot 2 \\
61 \cdot 15 \\
60 \cdot 9 \\
60 \cdot 15 \\
60 \cdot 05 \\
55 \cdot 45 \\
55 \cdot 45 \\
58 \cdot 1 \\
57 \cdot 95 \\
55 \cdot 0 \\
55 \cdot 1\end{array}$ & $\begin{array}{l}0 \cdot 418- \\
0 \cdot 552- \\
0 \cdot 041+ \\
0 \cdot 090- \\
1 \cdot 117+ \\
1 \cdot 275+ \\
0 \cdot 863+ \\
0 \cdot 896+ \\
0 \cdot 343+ \\
0 \cdot 298+ \\
0 \cdot 285+ \\
0 \cdot 384+ \\
0 \cdot 678+ \\
0.515+\end{array}$ & \begin{tabular}{|l}
$59 \cdot 724$ \\
$5 ! \cdot 641$ \\
$56 \cdot 185$ \\
$56 \cdot 103$ \\
$62 \cdot 328$ \\
$62 \cdot 195$ \\
$61 \cdot 063$ \\
$60 \cdot 959$ \\
$55 \cdot 835$ \\
$55 \cdot 751$ \\
$58 \cdot 432$ \\
$58 \cdot 337$ \\
$55 \cdot 733$ \\
$55 \cdot 624$
\end{tabular} & $\begin{array}{l}59 \cdot 641 \\
59 \cdot 655 \\
56 \cdot 098 \\
56 \cdot 108 \\
62 \cdot 207 \\
62 \cdot 155 \\
60 \cdot 964 \\
60 \cdot 934 \\
55 \cdot 751 \\
55 \cdot 746 \\
58 \cdot 337 \\
58 \cdot 332 \\
55 \cdot 624 \\
55 \cdot 607\end{array}$ & $\begin{array}{l}0.083 \text { loss. } \\
0.014 \text { gain. } \\
0.087 \text { loss. } \\
0.005 \text { gain. } \\
0.121 \text { loss. } \\
0.040 \text { loss. } \\
0.099 \text { loss. } \\
0.025 \text { loss. } \\
0.084 \text { loss. } \\
0.005 \text { loss. } \\
0.095 \text { loss. } \\
0.005 \text { loss. } \\
0.109 \text { loss. } \\
0.017 \text { loss. }\end{array}$ \\
\hline $\left.\begin{array}{c}\text { Mean of expts. } \\
\text { of expansion } \\
\text { Mean of inter- } \\
\text { polations ... }\end{array}\right\}$ & $30 \cdot 20$ & 3137 & 1238 & ...... & $\begin{array}{l}0.416+ \\
0.389+\end{array}$ & & & $\begin{array}{l}0.0968 \text { loss. } \\
0.0104 \text { loss. }\end{array}$ \\
\hline Corrected result. & $30 \cdot 20$ & 3137 & 1238 & ... & & & & 0.0855 loss. \\
\hline
\end{tabular}


condensation in the experiments of Table I. : also a certain quantity of cold would have been produced in the experiments given in Table III. The results are, however, such as might have been deduced à priori from any theory in which heat is regarded as a state of motion among the constituent particles of bodies. It is easy to understand how the mechanical force expended in the condensation of air may be communicated to these particles so as to increase the rapidity of their motion, and thus may produce the phænomenon of increase of temperature. In the experiments of Table III. no cold was produced, because the momentum of these particles was not permanently converted into mechanical power; but had the motion of the air from one vessel to the other been opposed in such a manner as to develope power at the outside of the jar, which might have been accomplished by means of a cylinder and piston, then loss of heat would have occurred, just as in Tables IV., V. and VI., where the force was applied in lifting the atmosphere of the earth.

It is quite evident that the reason why the cold in the experiments of Table IV. was so much inferior in quantity to the heat evolved in those of Table $I_{\text {s, }}$ is that all the force of the air, over and above that employed in lifting the atmosphere, was applied in overcoming the resistance of the stopcock, and was there converted back again into its equivalent of heat.

The discovery of Dulong*, that equal volumes of all elastic fluids, taken at the same temperature and under the same pressure, when suddenly compressed or dilated to the same fraction of their volume, disengage or absorb the same absolute quantity of heat, accords perfectly with these principles.

The mechanical equivalents of heat determined by the various series of experiments given in this paper are 823,795 , 820,814 , and 760 . The mean of the last three, which I take as least liable to error, is $798 \mathrm{lbs}$., a result so near $838 \mathrm{lbs}$., the equivalent which I deduced from my magnetical experiments, as to confirm, in a remarkable manner, the above explanation of the phanomena described in this paper; and to afford a new, and to my mind, powerful argument in favour of the dynamical theory of heat which originated with Bacon, Newton, and Boyle, and has been at a later period so well supported by the experiments of Rumford, Davy and Forbes. With regard to the detail of the theory, much uncertainty at present exists. 'The beautiful idea of Davy, that the heat of elastic fluids depends partly upon a motion of particles round * Annales de Chimie, vol, xli. p. 156. 
their axis*, has not, I think, hitherto received the attention it deserves. I believe that most phænomena may be explained by adapting it to the great electro-chemical discovery of Faraday, by which we know that each atomic element is associated with the same absolute quantity of electricity. Let us suppose that these atmospheres of electricity, endowed to a certain extent with the ordinary properties of matter, revolve with vast velocity round their respective atoms; and that the velocity of rotation determines what we call temperature. In an aeriform fluid we may suppose that the attraction of the atmospheres by their respective atoms, and that of the atoms towards one another, are inappreciable for all pressures to which the law of Boyle and Mariotte applies; and that, consequently, the centrifugal force of the revolving atmospheres is the sole cause of expansion on the removal of pressure. By this mode of reasoning, the law of Boyle and Mariotte receives an easy explanation, without recourse to the improbable hypothesis of a repulsion varying in a ratio different from that of the inverse square. The phænomena described in the present paper, as well as most of the facts of thermo-chemistry, agree with this theory ; and in order to apply it to radiation, we have only to admit that the revolving atmospheres of electricity possess, in a greater or less degree, according to circumstances, the power of exciting isochronal undulations in the æther which is supposed to pervade space.

The principles I have adopted lead to a theory of the steamengine very different from the one generally received, but at the same time much more accordant with facts. It is the opinion of many philosophers that the mechanical power of the steam-engine arises simply from the passage of heat from a hot to a cold body, no heat being necessarily lost during the transfer. This view has been adopted by Mr. E. Clapeyron in a very able theoretical paper, of which there is a translation in the 3rd part of Taylor's Scientific Memoirs. This philosopher agrees with Mr. Carnot in referring the power to vis viva developed by the caloric contained by the vapour, in its passage from the temperature of the boiler to that of the condenser. I conceive that this theory, however ingenious, is opposed to the recognised principles of philosophy, because it leads to the conclusion that vis vivn may be destroyed by an improper disposition of the apparatus: thus Mr. Clapeyron draws the inference, that "the temperature of the fire being from $1000^{\circ}$ (C.) to $2000^{\circ}$ (C.) higher than that of the boiler, there is an enormous loss of vis viva in the passage of the heat from the furnace into the boiler." Believing that the power

* Elements of Chemical Philosophy, vol. j. p. 94. 
to destroy belongs to the Creator alone, I entirely coincide with Roget and Faraday in the opinion, that any theory which, when carried out, demands the annihilation of force, is necessarily erroneous. The principles, however, which I have advanced in this paper are free from this difficulty. From them we may infer that the steam, while expanding in the cylinder, loses heat in quantity exactly proportional to the mechanical force which it communicates by means of the piston; and that on the condensation of the steam, the heat thus converted into power is not given back. Supposing no loss of heat by radiation, \&c., the theory here advanced demands that the heat given out in the condenser shall be less than that communicated to the boiler from the furnace, in exact proportion to the equivalent of mechanical power developed.

It would lengthen this paper to an undue extent were I now to introduce any direct proofs of these views, had I even leisure at present to make the experiments requisite for the purpose; I shall therefore reserve the further discussion of this interesting subject for a future communication, which I bope to have the honour of presenting to the Royal Society at no distant period.

Oak Field, near Manchester, June 1844.

LV. Outline of a New and General Mode of Transforming and Resolving Algebraic Equations. By JAMES CockLe, B.A., of the Middle Temple, Special Pleader*.

1. THE practical application of the following will be found in various papers which $I$ have had the honour of publishing in the Mathematician. The method is, however, here presented in an entirely novel form. Considered generally, its characteristic is, the effecting the proposed reductions by modifying the roots of an equation directly. By way of commencement, I have, for this purpose, generalised the assumption of Mr. Murphy $†$ (which is undoubtedly true for equations of the first four degrees), and assumed that the roots of the general equation of the $n$th degree, in $y$, are given by a set of expressions of which the type is

$$
y_{r}=\beta_{0}+\alpha^{r} \beta_{1}+\alpha^{2 r} \beta_{2}+\ldots+\alpha^{(n-1) r} \beta_{n-1}, \ldots
$$

where $\alpha$ denotes one of the $n$th roots of unity. It follows from this, that

$$
y_{1}+\alpha y_{2}+\alpha^{2} y_{3}+\ldots .+\alpha^{n-1} y_{n}=n \beta_{n-1} ;
$$

and, denoting the left-hand side of (2.) by $\phi(y)$, if $\phi(y)=0$, $\beta_{n-1}=0$.

* Communicated by T.S. Davies, Esq., F.R.S., F.S.A.

+ Philosophical Transactions, 1837, part I. 